\title{
Assessment of user happiness in campus open spaces
}

\author{
Alshimaa A. Farag \\ Effat University, Kingdom of Saudi Arabia \\ alshimaa_79@yahoo.com
}

Samaa R. Badawi

Mansoura University, Egypt

samaabadawi2002@gmail.com

Rahma M. Doheim

Assiut University, Egypt

mdoheim@yahoo.com

\begin{abstract}
There is a considerable amount of interest among scholars and urban designers in assessing and fulfilling a shared desire for happiness that is expressed by users of open spaces. The scope of this paper is limited to user experience in a university campus, and considerations around the impact of the setting and design of existing open spaces on stimulating positive feelings and happiness in students, and enhancing the all-round educational experience. The study is limited to young female students at the Effat University campus, in the Kingdom of Saudi Arabia, Jeddah City. This paper aims to assess the students' level of happiness on a university campus by examining the impact of the open spaces design and setting on the students. A cognitive map analysis is used to investigate the students' emotional experience of the open spaces on campus. Also, a questionnaire is used to investigate the students' preferable open spaces and the reasons for their preferences, which validate the results. The results showed that due to social and environmental conditions some decisions need to be made in response to outdoor temperatures and the spaces' settings in order to improve their design and make a significant positive impact on students' happiness. In addition, this could potentially result in a happier, healthier, and more efficient educational environment overall.
\end{abstract}

Keywords: happiness, subjective well-being, educational environment, open spaces, cognitive map, university campus, space setting

To cite this article:

Farag, A. A., Badawi, S., Doheim, R. M. (2019). Assessment of user happiness in Campus open spaces. The Journal of Public Space, 4(I), 45-64, DOI 10.3289I/jps.v4il.566

This article has been double blind peer reviewed and accepted for publication in The Journal of Public Space.

This work is licensed under a Creative Commons Attribution - Non Commercial 4.0 International License https://creativecommons.org/licenses/by-nc/4.0/ 


\section{Introduction}

The philosopher Aristotle said, "Happiness is the meaning and purpose of life". All human beings aspire to be happy and the United Nations General Assembly's 20I I Resolution recognised this pursuit of happiness as a fundamental human goal (UNESCO, 2016). Happiness is now one of the most researched topics in the twenty-first century, attracting scholars from around the world (Vega, 2016).

Many scholars are concerned with the subject of user experience on university campuses, and the impact of the setting and design of open spaces on the stimulation of positive feelings like happiness, satisfaction and well-being, and an overall enhancement of educational experience. When students feel happy and satisfied, and they are able to enjoy their environment, this aids learning and their development across physical, cognitive, emotional, moral and spiritual dimensions (Ahmadi-Afusi, et al., 20l4). According to a recent survey conducted by the Higher Education Policy Institute (HEPI) and Advance HE on more than 14,000 students, it was found that only 17 per cent of the students believed they were happy and considered their life to be worthwhile. This highlights a serious problem: among young people aged between 20 and 24, university undergraduates exhibit significantly lower levels of happiness compared to their contemporaries (Busby, 2018). The design of open space has a significant effect on students' feelings towards educational institutions, and as such plays a major role in learning processes. Attractive open spaces enhance students' opportunities for mental refreshment between classes, thereby increasing their performance levels in class. In addition, open spaces provide a place for physical activity and entertainment that helps in mitigating the negative feelings resulting from the stress of routine studying (AhmadiAfusi, et al., 20I4; Montgomery, 20I3). This study aims to assess students' happiness on a university campus by examining the impact of the design and setting of open spaces within the premises on the students. A cognitive map is used for data collection and a questionnaire employed to prove the results' validity. In addition, using the cognitive map as an assessment tool for studying happiness contributes to urban sociology research.

\section{Literature Review}

\section{I Happiness definitions}

Interest in happiness is not a recent phenomenon; the citizens of Rome adopted a God to symbolise Happiness (Montgomery, 20l4). Aristotle defined happiness according to three areas; feeling enjoyment, good performance and success, and spiritual life.

Additionally, Argyle and Crossland define happiness as a combination of positive feeling, lack of negative feeling and life satisfaction (Montgomery, 2013). Nowadays, the happiness issue is widely researched in social sciences to the point where, according to the ProQuest full-text database, the word "happiness" has been mentioned in research abstracts more than I70,000 times (Babincak, 20I8). Because of the excessive use of the word "happiness", the definition of happiness has been mixed up with another set of concepts, including leisure, euphoria, well-being, satisfaction, and quality of life (AhmadiAfusi, et al., 20I4). However, all these concepts are used by scholars to indicate people's evaluation of their lives (Cloutier, et al., 2014). These terms have been applied and used as interchangeable synonyms in several studies (MacKerron \& Mourato, 2013). 
However, the mix-up between happiness and other terms may cause ambiguity. Thus, the following section will discuss the different meanings and purposes of happiness. There is an overlap between the two terms happiness and satisfaction. Happiness is a result of a positive experience in which a person can say if s/he lives happily or not; while the concept of satisfaction is a result of an evaluation process in which a person can say if s/he is happy or not (Babincak, 2018). In this context, happiness has a broader meaning, and a longer-term influence. In other words, a happy person is satisfied, but a satisfied person is not necessarily happy.

Subjective well-being (SWB) is also one of the most common terms that has mightily overlapped the happiness concept. It is necessary to clarify that SWB is not synonymous with well-being. Well-being is a general concept that indicates how well people are doing in life according to social, health, and educational aspects and so on. The descriptor "subjective" in subjective well-being is added to limit the scope of a person's quality of life to the person's own perspective (Diener, et al., 2018). SWB is defined as people's evaluation of their lives, an evaluation that includes both the cognitive judgment of the standards of what constitutes "the good life" and an affective evaluation of feelings and emotions. In some studies, the term "life satisfaction" is used to refer to the cognition aspect of the evaluation and happiness often refers to the affect aspect (Okulicz-Kozaryn \& Valente, 20I8). This categorisation of cognitive and affect aspects limits the concept of happiness to emotional experiences and subjective evaluations. However, it is difficult to separate the two aspects in one assessment. The concept of happiness itself tackles the subjective construct of user experience, the assessment of which involves two aspects, the cognitive and the affect (Nor-Azzatunnisak, et al., 2017). This means that subjective well-being and happiness are synonyms and share similarities both in nature and in their respective components.

Likewise, Diener, et al. (2018) confirmed that people's emotions include an evaluative component which can provide evidence as to their level of life satisfaction. This means that the cognitive measure and affect measure in the evaluation process are connected and indeed used to support each other. However, a critical concern is raised by researchers that concerns the subjective nature of emotional experience which may cause it to differ from one person to another.

Moreover, a positive relationship between subjective well-being and happiness, and quality of life has been approved in several studies (Diener, et al., 2018). The concept of quality of life includes two perspectives: a "place-centered" perspective that focuses on the prevailing conditions a life is subject to and a "person-centered" perspective that tackles the person's direct experience of life. Consequently, the two perspectives are used for assessment. The "place-centered" perspective is based on objective criteria such as the frequency of use of entertainment spaces and facilities. While the "personcentered" perspective is subjective and is based on the experiences of the individual (Lloyd \& Auld, 2002).

MacKerron \& Mourato (2013) divided subjective well-being (SWB) into three categories; the evaluative SWB, eudemonic SWB, and hedonic or experienced SWB. The evaluative SWB is more cognitive in nature and concerns people's satisfaction with life as a whole. Whereas, the eudemonic SWB is based on reports concerning flourishing. Finally, the hedonic or experienced SWB represents people's mood, affect or emotion. All in all, there is a definite positive correlation between the three categories of SWB. 
Based on the above, the definition of happiness in this study is based on the "personcentered" perspective, and the "hedonic" concept that refers to experienced SWB or "happiness". The scope of the term happiness in this research indicates positive emotions rather than negative emotions in terms of how people assess their experience in open spaces on campus.

\subsection{Happiness, education, and open spaces}

The successful open space has a significant impact on human feeling and user behavior (Farag, 2016). The open space is the spatial context of the users' experience; therefore, it is essential to understand emotional experience as occuring within that context (Montgomery, 20I3). Designing a successful open space can stimulate students to feel happiness and an internal motivation towards happiness which they spend most of their lifetime searching for; designing such a space necessitates providing lighting and thermal comfort, using bright colors, installing appropriate furniture (Dadvand, et al., 2015; Wu, et al., 20I4), assuring safety (Pfeiffer \& Cloutier, 20I6), carefully curating urban forms (Jacobs, I96I; Leyden, et al., 20II), making amenities available (Bravo, 20I2), choosing a good location (Montgomery, 20I3), and maintaining cleanness, as living in a polluted, unclean environment has an unpleasant impact on its users' emotional experience. Environmental conditions have also been found to contribute to students' states of happiness (Cloutier \& Pfeiffer, 2015); climate and geography, air and water quality, and sustainability practices are all considered to be indicators for reporting levels of happiness and comfort (Leyden, et al., 20l I).

The design of outdoor spaces and the physical environment in campuses are found to be very influential factors in enhancing students' well-being, improving students' cognitive abilities and mental health, improving attention restoration, and giving students the possibility of a pleasant educational experience (Bratman, et al., 2012; Scholl \& Gulwadi, 20 I5; McFarland, et al., 2008; Lau, et al. 20I4; Ahmadi Afusi, et al., 20l4). Moreover, paying attention to open space and its role in enhancing students' emotional experience can relieve the stress of the studying routine and exams, and improve academic outcomes (UNESCO, 2016). In this respect, a study examined the impact of open space design on mitigating stress in university campuses in a compact urban setting (Lau, et al. 20l4). The present study found that a comprehensive design approach that applies three design strategies: landscape design, spatial design and green design practice is a healthy design approach to open spaces that helps to create opportunities for relaxing and releasing stress. It was found that if the campus' open spaces were designed according to this comprehensive approach they would actively promote staff and students' attention restoration, enhance well-being, improve mental health, and provide various levels of comfort for users.

There is substantial evidence surrounding the positive effect of nature and plants on a person's sense of well-being (Cohen, et al., 2013). Several studies have confirmed the link between access to open, natural, and green environments and feeling a sense of happiness. From a window overlooking a grassy green-coloured lawn or forest to living near a regional park, greenness makes a place more attractive and provides the opportunity for people to be in contact with nature. Additionally, greenness; improves physical and mental health where it encourages activities like gardening and doing exercise (Pfeiffer \& Cloutier, 2016); fosters cognitive development and learning 
outcomes (Larson, et.al, 2016); enhances friendly, supportive and helpful attitudes in students, making them less prone to violence and contributes to the feeling of belonging which in turn fosters trust. Nature brings out the good in us, helping build essential bonds between students and places (Montgomery, 2013).

Similarly, many studies have investigated how students' levels of happiness and satisfaction with the campus' outdoor environment contribute positively to their academic achievements and well-being. For example, a study in Texas university investigated the relationship between campus green spaces and the students' perception of the quality of life on offer (McFarland, et al., 2008). This study found that students who visited the green spaces more frequently and spent more time outdoors were more satisfied with the quality of life within the university and more capable of improving their academic performance than students who made less frequent visits to them and spent less time outdoors. Yet, some university planners have not given this issue priority.

The physical setting of an open space may also encourage or eliminate opportunities for social engagement among students. There is a strong link between having deep and fulfilling social relationships, feeling positive and happy, and being prevented from being isolated (Pfeiffer \& Cloutier, 2016; MontgoMery, 20I4). A study was conducted in a university in Saudi Arabia, which aimed to assess use preferences across the campus' outdoor spaces and to investigate the preferred pattern of activity within these open spaces. It was found that 36 per cent of students preferred the outdoor space with a setting which allowed for socialising and meeting with their colleagues, 30 per cent preferred the shaded outdoor spaces and around 14 per cent preferred the open space that features a well-maintained landscape. The student's preference was based on the physical setting, furnishing of seating spaces, green areas and shading devices. This explains the other finding that among the five measured preferred patterns of activities within outdoor spaces on campus the majority of students tend to socialise rather than use the outdoor spaces for studying, learning, passing-by or entertaining (Abdelaal, et al., 2017).

Conversely, a study in the University of Western Australia investigated how good academic achievements contribute to students' happiness and satisfaction rather than how students' happiness contributes to good academic achievement. This study revealed that there are different variables affecting students' happiness and satisfaction, in which some are significant and others are insignificant. The study determined that the top 4 variables are satisfaction with school work, good relationships with peers, proper time management, and a university with a good reputation (Chan, et al., 2005).

After all, the campus' urban design and landscaping significantly affects efforts to attract and recruit students to universities (Boyer, 1987; Hartley \& Morphew, 2008;

Klassen, 200 I), especially if the open spaces in campuses are kept in their natural form as this will not only bestow a venerable identity to the campus but also create a strong sense of community. Creating a healthy and pleasant attractive outdoor space on campuses should be one of the main priorities for universities (Griffith, 1994).

Promoting feelings of happiness can be employed to elevate overall happiness levels; decision makers can direct their policies towards using open space elements and landscapes to foster high levels of happiness in users (Vega, 2016). 


\subsection{Measuring happiness}

There is a global interest in the field of measuring happiness that has been growing over the past twenty-five years. At the beginning of the twentieth-century economists claimed happiness to be an unmeasurable variable. They claimed that efforts to quantify happiness in people are meaningless and that what is really at stake in terms of natural selection is survival, not happiness. However, modern research conceives happiness as being a measurable quantity, regardless of whether or not this is meaningful for economic purposes (Hossenfelder, 20I3).

Numerous organisations and many countries around the world have been working on measuring happiness and marketing the happiest countries to the world community. Therefore they have made the happiness standards a top priority (Larson, et.al, 2016). Countries like the United Kingdom of Great Britain and Northern Ireland, Australia, Canada, and Mexico have launched national projects to officially measure Happiness. World organisations have developed a happiness measurement process by initiating a series of indicators to measure happiness levels (Vega, 2016): the World Happiness Report, the Happy Planet Index, the World Values Survey and the Better Life Index are all global initiatives with the aim of measuring countries' levels of happiness. The Programme for International Student Assessment (PISA) is a worldwide study aiming to measure students' happiness in schools based on 22 criteria, under three broad categories: People, Process and Place (UNESCO, 20I6). All of these initiatives measure well-being under the umbrella concept of happiness and have been developing work on a large urban scale, that depends on many indicators that are not included in this research scope such as housing affordability, unemployment rate, and safety. In respect to the micro-scale of open spaces, there are numerous research-suggested tools for measuring users' happiness (Helliwell, et al., 2019). Despite the several tools that have been used to measure happiness, currently there is no research-confirmed "best tool" when it comes to measuring happiness (Nor-Azzatunnisak, et al., 20 I7). In the following part, the two tools used in measuring happiness in this research are discussed explicitly. However, it is worth mentioning here that there is a recent and more technological tool available, known as bio-statistical indicators. This tool provides objective measuring by using wearable technologies to collect data on bio-statistical indicators like skin reactivity, brain activity, surface skin temperature, and stress measures (Pfeiffer \& Cloutier, 2016). This method is still limited to application, it needs expensive equipment, requires medical settings, and is hard to apply on large number of people. Therefore, it will be excluded from this research.

\subsection{Self-report measure (Questionnaire)}

The self-report measure is one of the examples that is widely used and involves people being asked to evaluate their lives (Helliwell, et al., 2019), or simply asking them to provide an explicit judgment about the quality their life through responding to a questionnaire (Diener, et al., 20I8). Leyden, et al. (20II) claimed that asking people directly how happy they feel is a useful way to measure happiness, based on the assumption that they are the best judges of their happiness status. The self-report measure is a simple tool which empowers the researcher to direct questioning in a way that could help to unearth and deduce the way the respondents feel. The researcher 
can compose a series of questions using a Likert-type scale from I to 5, 7 or 10 points, where $\mathrm{I}$ indicates strongly disagree, and 5,7 or 10 indicate strongly agree (Pfeiffer \& Cloutier, 2016). In this case, it is an easy and applicable tool to employ when asking a big sample of people about their feelings, to uncover the reasons that caused happiness or unhappiness (Montgomery, 20I3).

Evaluating people's experience by asking direct questions may help in recognising their level of happiness. However, some studies reveal the flaws of asking direct questions for research purposes for example that people may be deceived about their emotions or provide unclear or incorrect answers. Moreover, the meaning of the questions may be perceived differently from one person to another depending on the context of the study and the respondent's reaction, resulting in different answers. Additionally, the flaw inherent in using this tool is that the respondents may start to answer the questions in a pattern, for example, repeatedly selecting option no. 6 in response to all the questions, or they may misunderstand the questions, both of which result in inaccurate answers (Augustin, Coleman, 2012). Accordingly, in order to have reliable and meaningful happiness measures, the person's emotions have to be stable over time, and not influenced by changeable factors such as weather or personal experiences. Also, people should be able to report their emotions. To overcome this dilemma, it is recommended that the questions be repeated several times over a period of time, and the number of happy or unhappy answers counted in order to calculate the percentage of answers that reflect the respondent's happiness (Diener, et al., 2018). Another way to increase the reliability of this tool is to consider the questionnaire design, asking a question in the beginning that is similar to the one asked at the end of the questionnaire, that way the consistency between the two answers can be examined (Chan, et al., 2005).

Therefore, depending only on the self-report measure (cognitive judgment) to reveal respondents' underlying feelings could mislead the research findings. Diener, et al. (2018) advise combining a broad array of measures that include both cognitive judgment and affective measurements.

\subsubsection{Cognitive Map}

The Cognitive Map is a technique that was pioneered by Lynch (1960) and has since been used extensively in research. It has been used to externalise what lies inside human minds regarding the surrounding environment and how they understand, perceive, assess and feel the built environment through the process of drawing. The users translate their emotional experiences through a series of psychological transformations in which people acquire, code, store and decode information about their spatial environment; its elements, relative locations, distances and directions, and overall structure (Rapoport, 1990). According to Nasar (1990), the users' feelings about their environment can be assessed and their assessment is an essential component of the perception process. The cognitive map is considered as a mental representation of the individual experiences (Ganji, et al., 2006; Laszlo, et al., 1996), and a form of visual aid to enhance our understanding of the thoughts of an individual or group (Kadriye \& Mehmet, 20I2). The cognitive map is a helpful tool to recall and test the emotional experiences of the users for the purposes of a happiness assessment. The lines they draw can reflect their feelings, for example, a straight line reflects that someone is stable, a wavy one reflects calmness and a jagged one gives a sense of anger and confusion (De Botton, 2008). 
Moreover, the cognitive map technique is tied to the "Environmental Preference" discourse, which concerns the places that people prefer more than other places. It has a long tradition in environmental psychology, cognitive responses to environments, natural or urban works (Bechtel \& Churchman, 2002).

Research using the cognitive map technique has been conducted on a sample of 30 students at the Selcuk University Campus in Turkey, to investigate how the students perceive the open spaces in their campus. The researchers used the drawing technique to restore the mental images in the users' minds and transform their thoughts into tangible drawings or "cognitive maps". The present study showed that the students disliked the areas that they have trouble understanding/perceiving, such as undefined and vacant areas. They mostly liked places such as sports facilities, festival areas, shopping centres, libraries, and cafeterias. The users preferred to actively use the open spaces in which they felt a sense of belonging. The social spaces within the campus area where students are seen to be gathering and activelt enjoying their lives are the most perceivable, meaningful and satisfactory places available to the students. This study concluded that the more preferable and admirable spaces are more memorable than others that are less so (Kadriye \& Mehmet, 2012). However, the study has not shown the reasons beyond students' preferences, which could be due to the fact that the study only used the cognitive map.

The cognitive map technique concerns providing data, on the ways individuals recognise their environment in a specific case (Sihombing, 20I4). However, the cognitive map has been accused of being a subjective tool that makes understanding and analysing diffcult due to variation in drawing abilities, in addition to inaccuracies in the drawings themselves (Imani \& Tabaeian, 2012). Moreover, a considerable challenge is posed by the random collection of rectangles and paths that are to be analysed and translated in order to investigate people's emotions. Additionally, the drawn plans may not have any resemblance to the actual areas (Augustin \& Coleman, 20I2).

In this research, the students' emotional affect and cognitive judgment of the open spaces on campus are assessed using two tools: the cognitive map and the questionnaire, for a comprehensive assessment.

\section{Methodology}

This study has a mixed methodology that combines both qualitative and quantitative methods. This study is conducted in a female institution in Saudi Arabia. The scope of this paper is limited to the user's emotional experience in a university campus, and the impact of the setting and design of the open spaces on stimulating positive feelings of "happiness" in order to enhance the educational experience. The open spaces in this research are defined as semi-public spaces according to the Hall (1982) classification. This is based on the fact that the spaces are neither entirely open nor closed, and are not accesible to the general public without express permission, or indeed male individuals due to cultural and social norms.

This study aims to assess the students' level of happiness in a university campus and examine the impact of the open spaces, their design and landscaping, on the students' feelings of happiness. A cognitive map analysis is used to investigate the students' emotional experience of the open spaces on campus to indicate memorable spaces. 
Also, a questionnaire is used to investigate the students' preferable open spaces and the reasons for their preferences, which validate the results.

This study is conducted as a single case study on the "Effat University campus". A single case study is selected rather than multiple-case study in order to provide a deep understanding of a specific representative case. Effat University is the first private university for female students in the Kingdom of Saudi Arabia, it was founded in 1999, and is located in the southern part of Jeddah city.

Effat University was designed as a modernist gated campus with an emphasis on integrating the open and closed spaces. The total area of Effat University is $82703.81 \mathrm{~m} 2$. The open spaces occupy 33.5 per cent of the total campus area. The make-up of this 33.5 per cent of open spaces consists of green gardens which are unevenly distributed over 27 per cent of the open spaces, while pathways and the paved central plaza area represent 73 per cent. Regarding the setting and design of the open spaces, most of the shading is created by palms, which are not in fact effective shading devices due to their being planted at a distance away from seating areas and pathways. In addition to the palms, there is only one wooden structure, which forms part of the outdoor cafeteria where students tend to gather outdoors, that provides shade: but the structure only shades 0.2 per cent of the total area of the open spaces (Farag, et al., 2019).

\section{I Data collection}

The survey was developed to determine the impact of physical components such as trees, green areas, furniture, shading devices and building facade colours in the open spaces on levels of happiness from the students' perspective.

Two tools were used to collect data:

- Cognitive map: The list of students were asked to draw their cognitive map of the university campus showing the different parts. The students had not been given any other instructions or orientation for drawing, only an A4 size sheet of paper on which to draw the campus map and a frame to draw inside.

- Questionnaire: the students were given a questionnaire with 25 questions that were split into two parts, the first part contained twenty closed-ended questions which asked directly about the preferable and unpreferable open spaces, and the positive and negative feelings that students have experienced in the campus' open spaces. The closed-ended questions were categorised into groups that tackled three issues in relation to the physical setting of the open spaces, which were: outdoor thermal situation, spaces' spatial configurations, and outdoor social life. The second part consisted of five open-ended questions that gave students the opportunity to describe the reasons behind their feelings and preferences and their suggestions for developing happy campus open spaces.

\subsection{Survey deployment}

The students who participated were first required to draw their cognitive map of the university campus, and then answer a questionnaire that included different types of questions. Thirty students volunteered to help distribute and collect the A4 sheets containing the cognitive map exercise and the questionnaire. The actual sample comprised of I 100 students from all majors. Only 900 students completed the survey. 200 responses were excluded for different reasons that had the potential to impact the credibility of the results. The selection of this sample was limited to students who had 
spent at least two years on the university campus. The time they had spent on the university campus would have allowed the students to develop feelings towards the campus' open spaces. This would aid them in restoring their perceptual image about the university while drawing the cognitive map, setting them apart from new students. Also, the survey was deliberately conducted in September, when the climate in Jeddah city is considerably hot and arid. The questionnaire form and the cognitive map request were submitted to the Research Ethics Institutional Review Committee (REIRC) at Effat University for review and approval.

\subsection{Data analysis}

The students' cognitive map drawings have been analysed to determine which open spaces are most memorable and represented. Also, the symbols, shapes, and nicknames that students applied on their cognitive maps indicated their feeling towards campus open spaces.

The questionnaire analysis provided more information regarding students' preferences, feelings, and happiness stimulators from the students' perspective.

The researchers used the content analysis method to analyse, categorise and organise both visual and verbal materials through both students' cognitive maps and the openended questionnaire, respectively, to find a pattern.

The analysis of the visual material included reviewing shapes, colours, textures, proportions, assortments of decorative elements and/or other parameters. A peer review was conducted to validate and explain the symbols and drawings. On the other hand, the analysis of the verbal material included reviewing the repeated words and phrases to investigate the further meanings lying beyond. The objective judgments of the questionnaire were compared to the subjective translation of the user's cognitive map for further validation.

\section{Results and Discussion}

The results of using both tools helped in comprehensively assessing the students' feelings and emotional experience of the campus' open spaces, and the happiness stimulators in those open spaces, which are discussed in the following section.

\section{I The memorable space}

The results showed that students' assessment of the open spaces depended first on memorising the space, then on focusing on how they evoke strong feelings of happiness or unhappiness.

In respect to the cognitive map method, the students were asked to draw a map showing the different parts of the campus. Surprisingly, about 45 per cent of students did not draw any open spaces in their maps, neither did they label the spaces. The students only drew zoning diagrams for the campus' different buildings. This could be due to four possible reasons: I) the open spaces are not recognised or clear enough in students' minds because it is not part of their daily route through the campus, not activated within their educational routine, or they don't spend enough time in it (see Figure I), 2) the students did not fully understand what they had to draw, or to what extent they should add urban details, 3 ) the quality of the students' drawings due to lack 
of interest, lack of time, or lack of drawing skills and 4) the students' disregard towards these spaces for emotional reasons, for example, experiencing undesirable situations. It is difficult to know which possible reason is most likely to be ratified by depending solely on cognitive maps, unless one asks direct questions. However, 55 per cent of students referred to the open spaces by drawing or labeling them on their cognitive maps in different ways that will be discussed later. The number of times that each open space appeared on students' cognitive maps were counted, as shown in Figure 2 and 3.
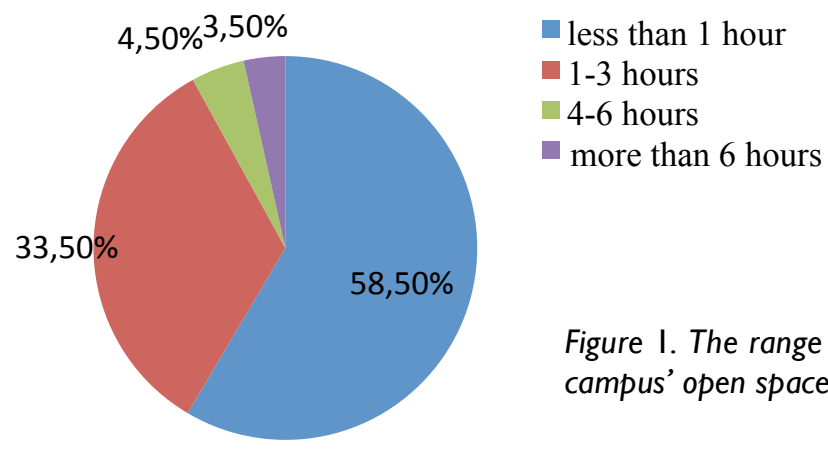

Figure I. The range of time periods the students have spent in the campus' open spaces.

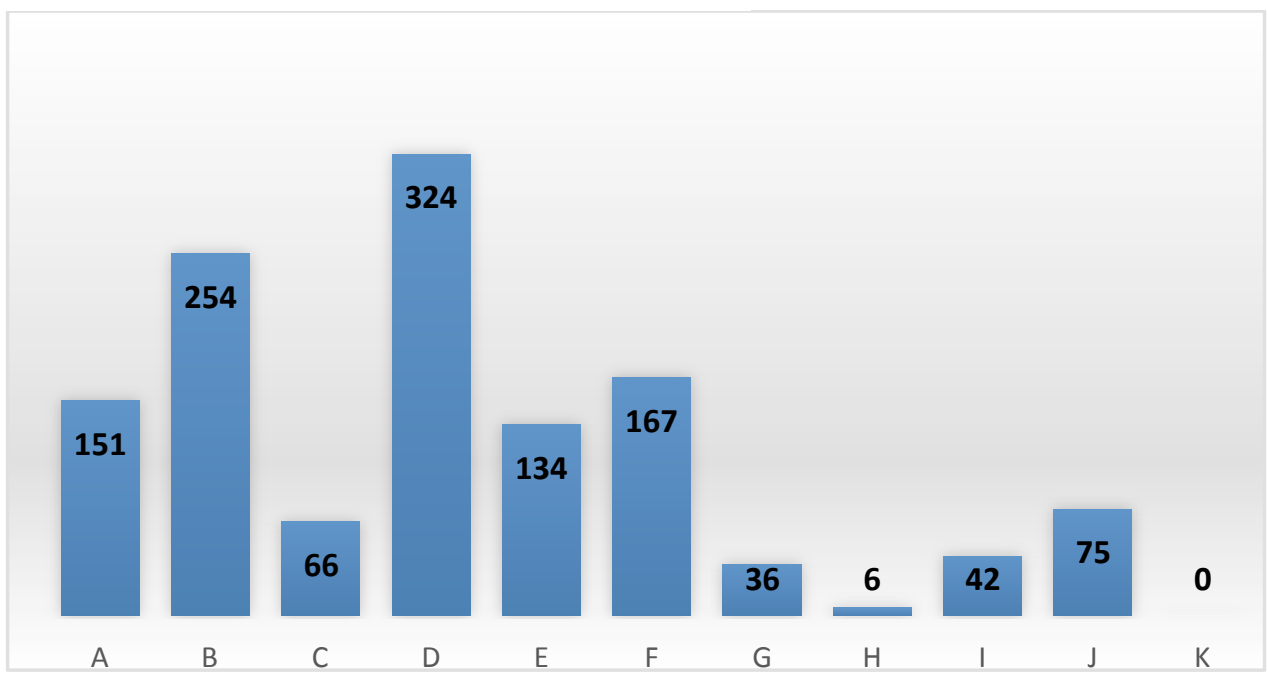

Figure 2. The number of times that each open space appeared on students' cognitive maps.

On the other hand, the students answered the questionnaires and directly selected the open spaces that evoked feelings of happiness or unhappiness. Surprisingly, the most selected spaces were (B and $D)$, which were the most memorable spaces in the students' cognitive maps. This means that the students remember, and perceive the spaces that most evoke their emotions. 


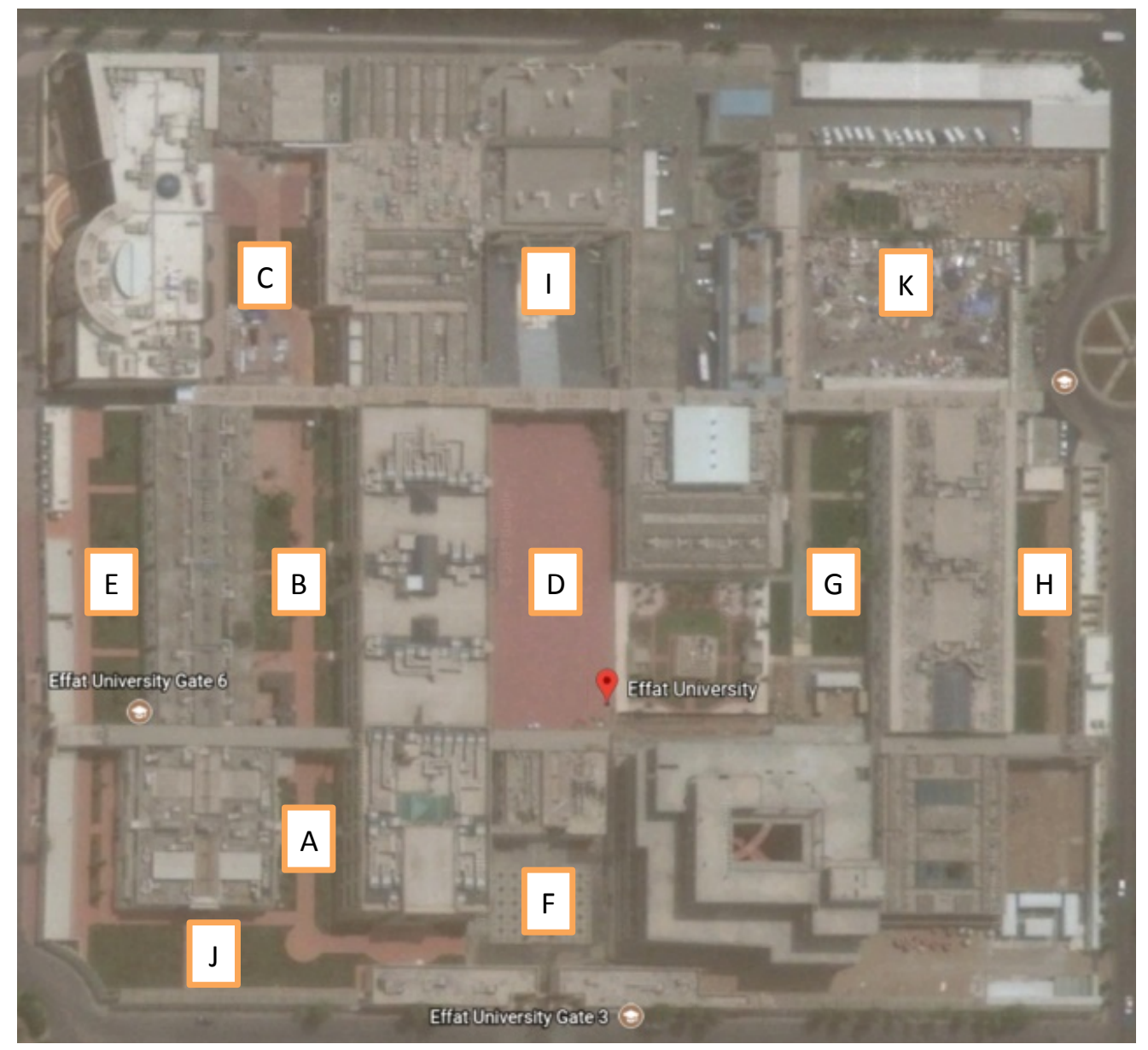

Figure 3. The campus' open spaces.

\subsection{The Happy and Unhappy Open Spaces}

Based on the cognitive map analysis, the students used different types of lines, shapes, and terms to represent their mental images of the open spaces. However, there was no concrete evidence of what they actually feel. In the questionnaire, 80 per cent of students selected space (B) to be the space where they feel happy, and 73 per cent of them selected space (D) to be the space that most evokes negative feelings and unhappiness. (see Figure 4 / 7). 

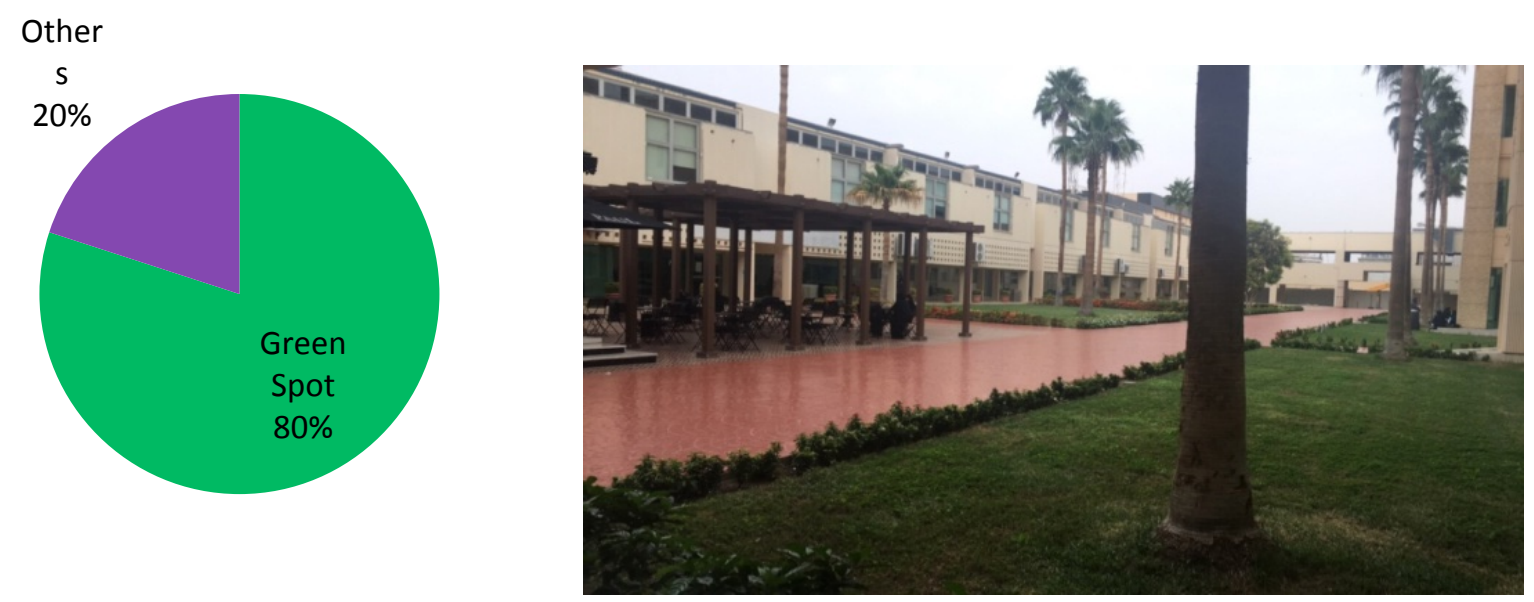

Figure 4 (left). The green spot is the happiest space according to the majority Figure 5 (right). Space (B) is the second highest perceived space and the happiest space
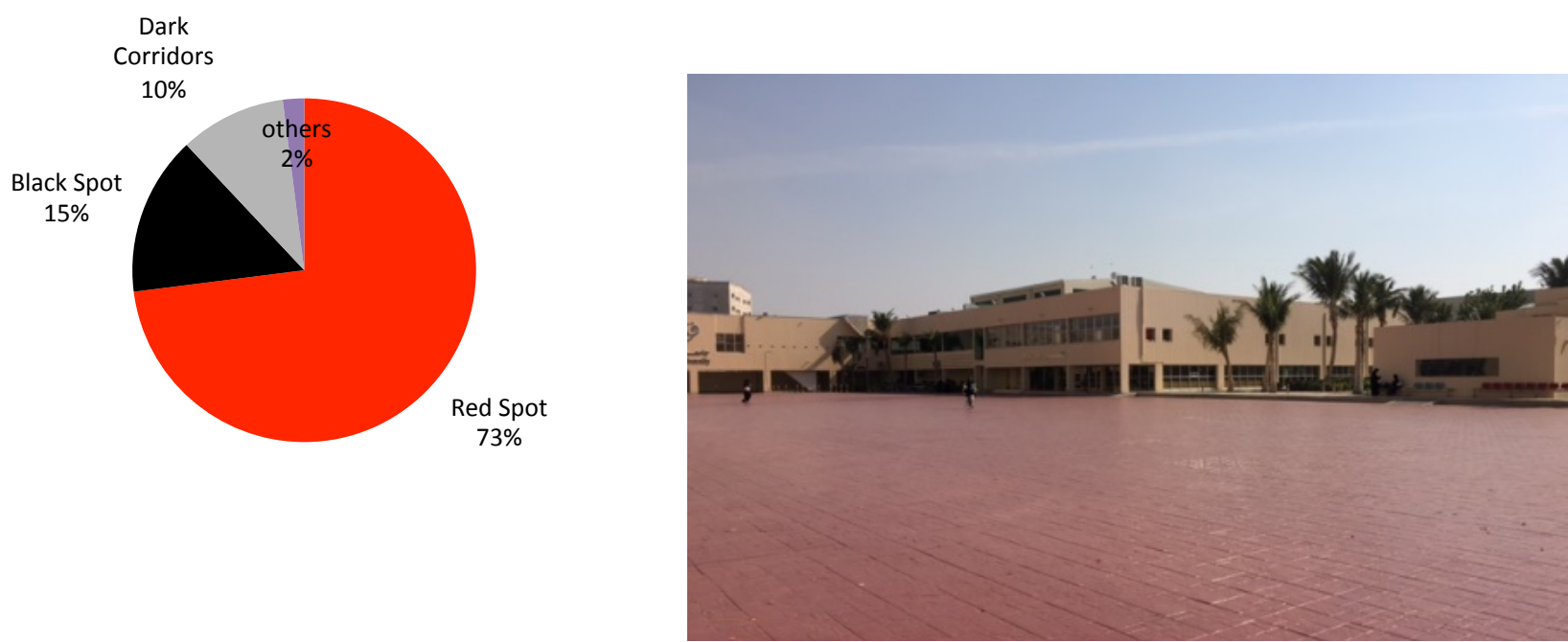

Figure 6 (left). The red spot is the unhappiest space according to the majority Figure 7 (right). Space $(D)$ the highest perceived space and the unhappiest space

It is worth mentioning that both spaces (B) and (D) are the most perceived by students according to cognitive map analysis. Moreover, the open space that appeared most on the cognitive map was space (D), which was considered the unhappiest space according to the questionnaire results. The second space that appeared most was space (B), which was considered the happiest space according to the questionnaire results. These results contradict the argument presented by Kadriye \& Mehmet (20I2), where they reveal that the most memorable spaces are not necessarily the happiest ones that evokes good feelings. According to this study, unhappy feelings contain more potential to evoke emotions in students' minds than happy feelings, and this could impact on their cognitive judgment. 


\subsection{Space representation}

The students used different ways to represent their feelings toward the open spaces. In the questionnaire, they used verbal nicknames for some spaces, especially the happy and unhappy ones (space B and D). Space (B), the happy one, has two nicknames, the most repeated is "Paul area", and its other nickname is "Green Spot". Space (D), the unhappy one, has been named the "Red Spot". Another space which was given a nickname is space (C), and it was named the "Black Spot".

Space (B), the Paul or the Green Spot, features a shaded cafe called Paul which students refer to as being a preferable gathering point, in addition to many more green areas than seen anywhere else on campus which students consider as constituting a good view. Space $(D)$ is a central space featuring red-coloured tiles that students dislike for many reasons including that it is unshaded and mostly sunny all day long and that it is relatively huge compared to the human scale. The Black Spot $(C)$ is a wide area of black asphalt that students disliked because the wide unshaded area has no green areas and is mostly abandoned. The nicknames given to spaces might refer strongly to certain elements in a space that produces positive or negative feelings.

In the cognitive map methodology, the way to translate the students' feelings is to analyse their visual drawings. The students used words, lines, shapes, colours, and 2D and 3D sketches. The words were the easiest way to understand how they felt. For example, some students replaced the common term "Red Spot" with "Dead Spot": which indicates clearly that students have a negative feeling towards this open space. Regarding the use of lines, shapes, colours, and 2D and 3D sketches, students represented the spaces in three ways:

I. Drawing landscape elements like trees, palms, grass, green boxes, flowers and seating.

2. Drawing a wide variety of lines and shapes in terms of continuity, stability, colour, scale and proportion.

3. Drawing symbolic representations for real objects like columns, steps and kiosks.

\begin{tabular}{|c|c|c|c|}
\hline Space & Landscape elements & Lines and shapes & Objects \\
\hline A & 70 & 30 & 0 \\
\hline B & 117 & 49 & 171 (Paul kiosk) \\
\hline C & 3 & 35 & 0 \\
\hline D & 10 & 157 & 0 \\
\hline E & 63 & 27 & 0 \\
\hline F & 28 & 0 & 125 (Columns) \\
\hline G & 17 & 0 & 0 \\
\hline H & 3 & 0 & 0 \\
\hline I & 0 & 0 & 25 (Steps) \\
\hline
\end{tabular}


Table I: open space representation in the students' cognitive maps

Space (B), the happy one, was mostly represented with the drawing of landscape elements and objects (kiosk). Whereas space (D), the unhappy space, was represented with jagged and shaky lines and irregular shapes.

Controversially, it is noted that students show more attentiveness and interest in drawing happy spaces, even elaborating more details that do not necessarily exist. The students drew more details when it came to representing green plots, grass, furniture and architectural details, and used green colours, dots and clear lines to construct their representational images. The unhappy spaces like space (D) and (C) were drawn carelessly, they were largely empty and featured shaky crossed lines, hatching and crosshatched polygons, and were drawn exclusively in shades of black.

This indicates that the students' mental images were a mix of existing details and other imaginary details arising from their perception, which is a result of the interaction between their positive or negative emotional experiences with the physical setting of the space. This emotional experience influences students' cognitive judgment, and the interaction between their emotional experience with the physical setting of the space enforces their mental image. The mental images confirm the feelings that students expressed in the questionnaire. This illustrates the importance of using the cognitive map along with a questionnaire to pair students' feelings with their cognitive judgments to increase the reliability to the results.

\subsection{Happiness and unhappiness stimulators}

In the open-ended questionnaire the students responded directly to what makes them happy, as shown in figure (8). According to their responses, access to green areas is the element most crucial in stimulating happiness, followed by good weather. What stimulates unhappy feelings, as shown in figure (9) is the hot weather which is the primary reason for their discomfort and resulting unhappiness is open spaces.

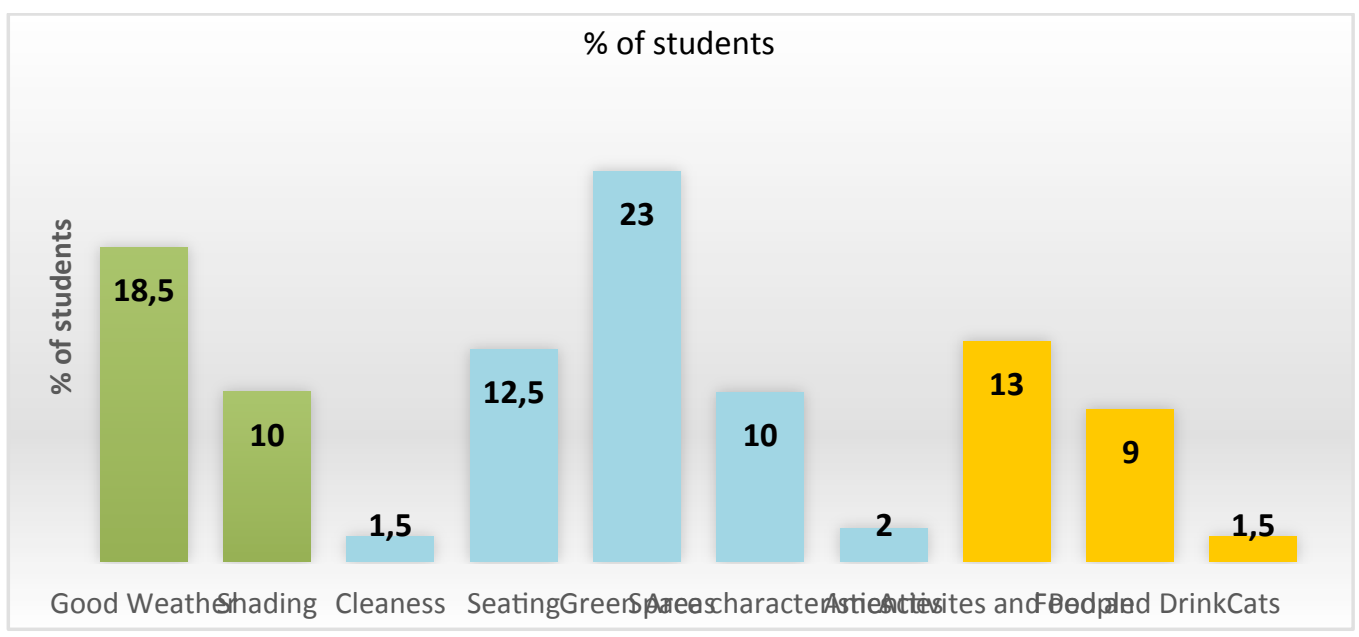

Figure 8. The happiness stimulators according to the questionnaire 


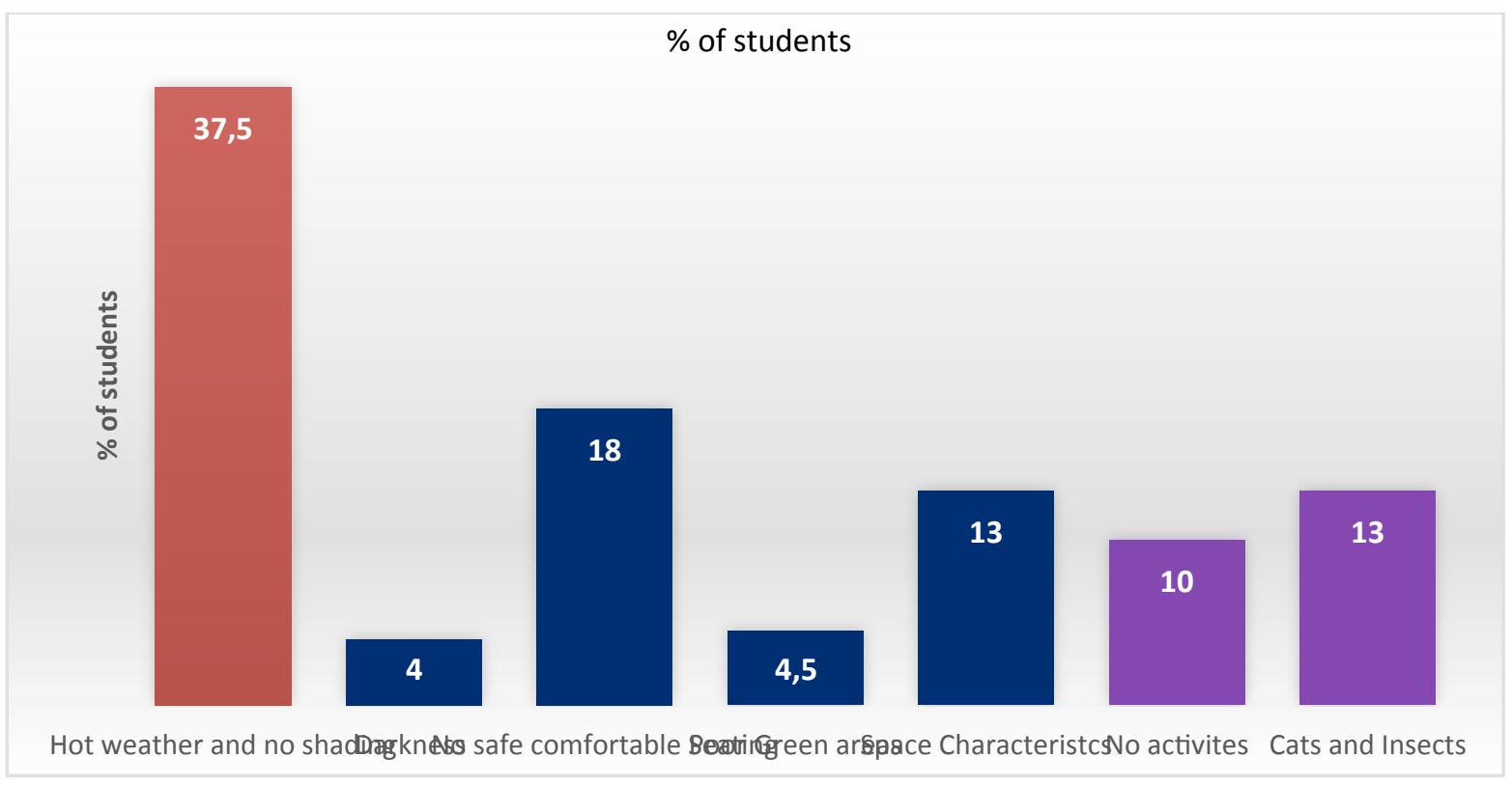

Figure 9. The unhappiness stimulators according to the questionnaire

On the other hand, using cognitive maps to understand the happiness stimulators is inapplicable especially when it comes to the intangible elements like weather for example. Students drew the landscape elements, green boxes, amenity locations, and seating to represent their good mood; but more than simply drawing abilities are required to represent enjoyment, social interaction, good educational environment, good weather or safety. The questionnaire is essential to investigate the happiness stimulators, which is difficult to investigate using the cognitive map. The students' answers have clarified the happy and unhappy stimulators as follows.

\subsection{Environmental stimulators}

About 76 per cent of students believe that the weather greatly affects their mood. Similarly, 50 per cent prefer to move through the indoor, closed air-conditioned corridors, rather than suffer the hot weather outside.

\subsubsection{Urban stimulators}

The urban and physical characteristics of the open spaces affect students' feelings. About 72 per cent of students experience negative feelings due to the buildings' colours and forms. The building's colours and forms make students feel bored. Also, 30 per cent of students think that narrow tunnels, which are not sufficiently illuminated, cause them to feel unhappy and gloomy. In addition, students indicated that they feel a sense of emptiness and a loss of human scale in the huge spaces. Students emphasised that landscape elements including shading, seating, and green evoke positive feelings.

\subsubsection{Social stimulators}

The design of campus open spaces has an important role in encouraging social interaction among students. According to the questionnaire, about 46 per cent of 
students see that the design of the campus open spaces is limiting the social interaction between students and instructors. Regarding the students' activities within the campus open spaces, and according the classification by Jan Gehl (20I I), Figure 7 shows that the students practice social, optional and necessary activities in the campus open spaces. However, those activities were mostly practiced in space (B) where the landscape elements encourage active collaboration between students. According to Gehl (20II), space (B) is proven to be a successful open space as it is characterised by a gentle engagement between necessary, optional and social activities. On the other hand, Space (D) only encourages necessary-type activities such as moving because it lacks a setting that encourages other types of activities.

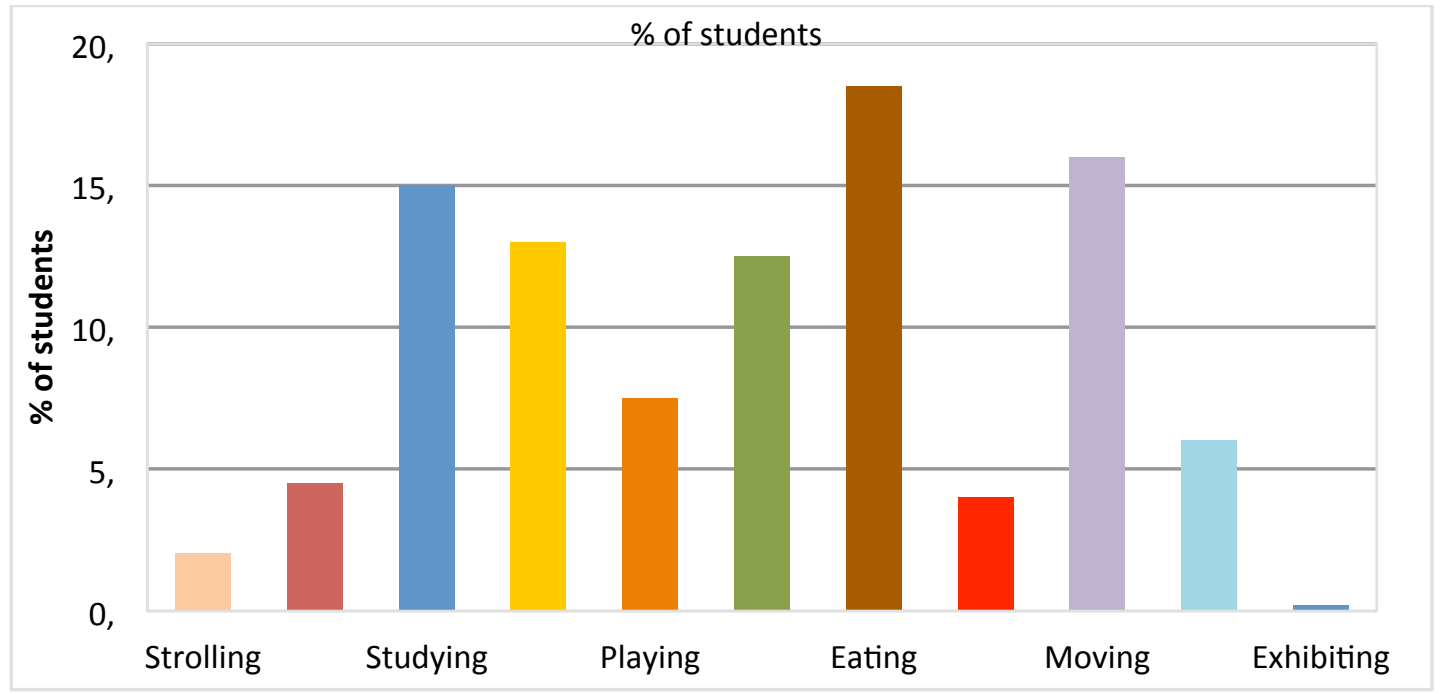

Figure 10. Type of activities the students have practiced in the campus' open spaces.

\section{Conclusion}

This paper aims to assess the students' level of happiness in a university campus and examine the impact of the design of open spaces and their settings on students' feelings of happiness. This study proves that space design and setting impact on the students' feelings of happiness. The students selected emotionally and cognitively preferable spaces that; evoke positive feelings and happiness; that have access to green areas; are thermally comfortable; and are well furnished with seating and shading devices that allow for social interaction. On the other hand, they selected unhappy spaces that were thermally uncomfortable, insufficiently lit, lacking in a sense of the human scale, and lacking in high-quality landscape elements.

The concept of happiness itself tackles the subjective construct of user experience, the assessment of which features two aspects, the cognitive and affect. In order to assess those two aspects, two tools were combined for a comprehensive assessment: the cognitive map and the questionnaire, as depending only on one method is not advised. This research concludes that emotional experience influences students' cognitive judgment. Additionally, that the interaction between the students' emotional experience and the physical setting of the open spaces enforces their mental image. Moreover, the 
mental image confirmed the feelings that students expressed in the questionnaire. This concludes the importance of using a cognitive map along with a questionnaire when assessing feelings in order to add more reliability to the results.

The students feel, perceive, and remember mostly what evokes their emotions. However, the highest memorable space is not necessarily the happiest one that evokes good feelings. According to this study, it is possible that unhappy feelings would potentially evoke emotions in and influence students' minds much more than happy feelings, and it could impact their cognitive judgment.

The interaction between the students' positive or negative emotional experiences with the physical setting of the space affected their mental image. In this study, the students drew more details in the depictions of happy spaces while giving less attention to detail when it came to drawing spaces they disliked. This concludes that stimulating happy feelings enhances students' perceptual image and positively influences their interaction with open spaces.

In order to make a shift towards a happier and more efficient educational environment, it is recommended that the campus' open spaces be developed by; spreading and expanding green areas across campus to enhance the space imageability; increasing the number of shading devices, plantations and trees to enhance the level of thermal comfort in the open spaces; and providing comfortable seating that promotes social activities and interaction between students and instructors.

\section{References}

Abdelaal, M., Doheim, R., Abdelaal, D. (2017). A framework for assessing the efficiency of outdoor spaces within university Campus: a case study of Effat university, Jeddah. In conference of Meamaryat International Conference, 18-20 April, Jeddah.

Ahmadi Afusi, Z., Zarghami, Z., \& Mahdinejad, J. (2014). A Study on Designing Open Space School and its Relation. with Improving Happiness among Students. Indian Journal of Fundamental and Applied Life Sciences, 4(S3), 924-31.

Augustin, S., \& Coleman, C. (20I2). The designer's guide to doing research: Applying knowledge to inform design. John Wiley \& Sons.

Babincak, P. (2018). Subjective Happiness in Slovakia: Reliability and Validity of Measuring Happiness through the Subjective Happiness Scale. European Journal of Mental Health, I3(2), III-132.

Bechtel, R. B., \& Churchman, A. (2002). Handbook of Environmental Psychology John Wiley \& Sons. Inc.: Hoboken, NJ, USA.

Boyer, E. L. (1987). College: The undergraduate experience. The Carnegie Foundation for the Advancement of Teaching. New York: Harper Collins. Find this author on.

Bratman, G. N., Hamilton, J. P., \& Daily, G. C. (20/2). The impacts of nature experience on human cognitive function and mental health. Annals of the New York Academy of Sciences, 1249(I), II8-136.

Bravo, L. (20I2). Public spaces and urban beauty. The pursuit of happiness in the contemporary European city. In Pinto da Silva, M. (ed.), EURAUI2 Porto | Espaço Público e Cidade Contemporânea: Actas do $6^{\circ}$ European symposium on Research in Architecture and Urban design, Porto, Faculdade de Arquitectura da Universidade do Porto (FAUP).

Busby, E., (2018). Fewer university students say they are happy and believe lives to be worthwhile, survey finds. Independent, News, Education, Education News, 7 June. 
Chan, G., Miller, P. W., \& Tcha, M. (2005). Happiness in university education. International Review of Economics Education, 4(I), 20-45.

Cloutier, S., \& Pfeiffer, D. (2015). Sustainability through happiness: A framework for sustainable development. Sustainable Development, 23(5), 317-327.

Cloutier, S., Larson, L., \& Jambeck, J. (2014). Are sustainable cities "happy" cities? Associations between sustainable development and human well-being in urban areas of the United States. Environment, development and sustainability, 16(3), 633-647.

Cohen, S., Evans, G. W., Stokols, D., \& Krantz, D. S. (2013). Behavior, health, and environmental stress. Springer Science \& Business Media.

Dadvand, P., Nieuwenhuijsen, M. J., Esnaola, M., Forns, J., Basagaña, X., Alvarez-Pedrerol, M. \& Jerrett, M. (2015). Green spaces and cognitive development in primary schoolchildren. Proceedings of the National Academy of Sciences, I I2(26), 7937-7942.

De Botton, A. (2008). The architecture of happiness. Vintage.

Diener, E., Lucas, R. E., \& Oishi, S. (2018). Advances and open questions in the science of subjective well-being. Collabra. Psychology, 4(I).

Farag, A. A., Doheim, R. M., \& Badawi, S. (2019). Evaluating Heat Island Effect at University Campus with Reference to LEED v4. Resourceedings, 2(I), I-I3.

Farag, A. (2016). A user definition of near home open space. In conference of EDRA48 Madison - Voices of Place: Empower, Engage, Energize, Madison, USA. (Pp. 139-147).

Ganji, S. K., Potula, I., Ambati, V. N. P., Rao, B., Ganji, S. K., \& Ganji, S. K. (2006). Image representation, scaling and cognitive model of object perception. Cognitive Processing, $7(\mathrm{I})$, 37-39.

Gehl, J. (20II). Life between buildings: using public space. Island press.

Griffith, J. C. (1994). Open space preservation: An imperative for quality campus environments. The Journal of Higher Education, 65(6), 645-669.

Hall, E. (1982). The Hidden Dimension. Anchor Books Editions.

Hartley, M., \& Morphew, C. C. (2008). What's being sold and to what end? A content analysis of college viewbooks. The Journal of Higher Education, 79(6), 67I-69I.

Helliwell, J. F., Shiplett, H., \& Barrington-Leigh, C. P. (2019). How happy are your neighbours? Variation in life satisfaction among 1200 Canadian neighbourhoods and communities. PloS one, |4(1), e021009|.

Hillier, B., \& Hanson, J. (1989). The social logic of space. Cambridge University Press.

Hillier, B., \& Hanson, J. ( 1984). The Social Logic of Space, Cambridge University Press.

Hossenfelder, S. (2013). On the problem of measuring happiness. Interdisciplinary Description of Complex Systems: INDECS, I I (3), 289-30I.

Imani, F., \& Tabaeian, M. (20I2). Recreating mental image with the aid of cognitive maps and its role in environmental perception. Procedia-Social and Behavioral Sciences, 32, 53-62.

Jacobs, J. (196I). The death and life of great american cities, Random House, New York.

Kadriye, T., Mehmet, T. (20I2). Visual presentation of mental images in urban design education: cognitive maps. Procedia - Social and Behavioral Sciences 5I, $573-582$.

Klassen, M. L. (200I). Lots of fun, not much work, and no hassles: Marketing images of higher education. Journal of Marketing for Higher Education, I0(2), II-26. 
Larson, L. R., Jennings, V., \& Cloutier, S. A. (2016). Public parks and wellbeing in urban areas of the United States. PLoS One, II (4), e0I532I I.

Laszlo, E., Artigiani, R., Combs, A., \& Csányi, V. (1996). Changing visions: Human cognitive maps: Past, present, and future. Praeger Publishers/Greenwood Publishing Group.

Lau, S. S. Y., Gou, Z., \& Liu, Y. (20I4). Healthy campus by open space design: Approaches and guidelines. Frontiers of Architectural Research, 3(4), 452-467.

Leyden, K. M., Goldberg, A., \& Michelbach, P. (20II). Understanding the pursuit of happiness in ten major cities. Urban affairs review, 47(6), 86I-888.

Lloyd, K. M., \& Auld, C. J. (2002). The role of leisure in determining quality of life: Issues of content and measurement. Social indicators research, 57(I), 43-7I.

Lynch, K. (1960). The image of the city (Vol. II). MIT press.

MacKerron, G., \& Mourato, S. (20I3). Happiness is greater in natural environments. Global environmental change, 23(5), 992-1000.

McFarland, A. L., Waliczek, T. M., \& Zajicek, J. M. (2008). The relationship between student use of campus green spaces and perceptions of quality of life. HortTechnology, I8(2), 232-238.

Montgomery, C. (2013). Happy city: Transforming our lives through urban design. Macmillan.

Montgomery, C. (20I4). Building Happiness. In BT Group, Connected Worlds (pp. 69-7I). British Telecom.

Nasar, J. L. (1990). The evaluative image of the city. Journal of the American Planning Association, 56(I), 4I-53.

Nor-Azzatunnisak, M., Roseliza-Murni, A., Manap, J., \& Hoesni, S. M. (2017). Selecting Appropriate Happiness Measures and Malleability: A Review. International Journal of Academic Research in Business and Social Sciences, 7(I I), 1082-1099.

Okulicz-Kozaryn, A., \& Valente, R. R. (2018). Livability and Subjective Well-Being Across European Cities. Applied Research in Quality of Life, I-24.

Pfeiffer, D., \& Cloutier, S. (2016). Planning for happy neighborhoods. Journal of the American planning association, 82(3), 267-279.

Rapoport, A. (1990). The meaning of the built environment: A nonverbal communication approach. University of Arizona Press.

Scholl, K. G., \& Gulwadi, G. B. (2015). Recognizing Campus Landscapes as Learning Spaces. Journal of Learning Spaces, 4(I), 53-60.

Sihombing, A. (2014). Drawing Kampung through cognitive maps case study: Jakarta. APCBEE procedia, 9, 347-353.

UNESCO. (2016). Happy Schools! A framework for learner wellbeing in the Asia Pacific. Paris, France: UNESCO the United Nations Educational, Scientific and Cultural.

Vega, J. D. J. G. (2016). Happiness and Quality of Life in Mexico: Conceptual and Geographical Considerations. In Handbook of Happiness Research in Latin America (pp. 463-475). Springer, Dordrecht.

Wu, C. D., McNeely, E., Cedeño-Laurent, J. G., Pan, W. C., Adamkiewicz, G., Dominici, F. \& Spengler, J. D. (20I4). Linking student performance in Massachusetts elementary schools with the "greenness" of school surroundings using remote sensing. PloS one, 9(I0), el08548. 